\title{
Regulation of gene expression in endothelial cells: the role of human follicular fluid
}

\author{
R Gruemmer ${ }^{1}$, L Klein-Hitpaß ${ }^{2}$ and J Neulen ${ }^{3}$ \\ ${ }^{1}$ Deparment of Anatomy, University of Essen, Hufelandstr. 55, D-45122, Essen, Germany \\ ${ }^{2}$ Department of Cell Biology, University of Essen, Essen, Germany \\ ${ }^{3}$ University Clinic for Gynecologic, Endocrinology and Reproductive Medicine, RWTH Aachen, Germany
}

(Requests for offprints should be addressed to R Gruemmer; Email: ruth.gruemmer@uni-essen.de)

\begin{abstract}
A precise regulation of angiogenesis is a prerequisite for an adequate maturation of ovarian follicles. Despite the production of vascular endothelial growth factor (VEGF) by granulosa cells in antral follicles, angiogenesis is restricted to the theca cell layer. The maturing follicle remains avascular before ovulation, implying regulatory mechanisms which prevent premature follicular vascularization. In order to investigate the role of follicular fluid and of granulosa cells in the regulation of endothelial gene expression, human umbilical vein endothelial cells (HUVECs) were incubated in vitro with media conditioned with human follicular fluid obtained from individual patients undergoing oocyte retrieval for in vitro fertilization procedures or with culture medium conditioned by human granulosa cells respectively. Using microarray technology, the gene expression pattern was compared between untreated monolayers of HUVECs and HUVECs treated either with follicular fluid or with granulosa cell conditioned media. We identified a total of 15 genes that were significantly up-regulated and 11 genes that were significantly down-regulated in endothelial cells treated with follicular fluid at least 2.5 -fold in more than $70 \%$ of comparisons. Up-regulated genes involved in angiogenesis were the anti-angiogenic factors gro-beta (16.5-fold), angiopoietin-2 (3.9-fold), alpha-2-macroglobulin (24.3-fold) and the pro-angiogenic factors E-selectin (5-3-fold) and vascular cell adhesion molecule-1 (VCAM-1) (4.4-fold), whereas a significant down-regulation of the pro-angiogenic genes fibulin-5 (3.5-fold) and elastin (14.9-fold) could be observed. Culturing of HUVECs with conditioned medium from cultured human luteinized granulosa cells demonstrated a similar regulatory pattern of gene expression for fibulin-5, elastin, gro-beta, and E-selectin. The gene regulation in endothelial cells by follicular fluid could be confirmed by RT-PCR for gro-beta, angiopoietin-2, elastin, fibulin-5, and E-selectin. The present work reveals that compounds secreted by granulosa cells lead to the expression of anti-angiogenic factors on the transcript level in endothelial cells and thus could help to explain the temporal and spatial discrepancy between the high expression of VEGF and the restricted angiogenesis in the preovulatory follicle.
\end{abstract}

Journal of Molecular Endocrinology (2005) 34, 37-46

\section{Introduction}

Angiogenesis is paramount in pathophysiological processes like wound healing and tumor growth. It is a rare event under physiological conditions in adults; it is restricted in the female reproductive tract to follicular development, corpus luteum formation, and uterine endometrial proliferation during the menstrual cycle (Findlay 1986, Reynolds et al. 1992). These reproductive tissues reveal tightly regulated cyclic growth including a number of programmed angiogenic processes especially during folliculogenesis and corpus luteum formation (Moor \& Seamark 1986, Augustin 2000, Fraser \& Wulff 2001). It is well known that with the development of the corpus luteum after ovulation vessels grow from the thecal vascular plexus into this developing endocrine gland and a number of factors promoting angiogenesis have been demonstrated in granulosa cells such as vascular endothelial growth factor (VEGF), fibroblast growth factor (Yan et al. 1993, Kamat et al. 1995, Neulen et al. 1995, Redmer \& Reynolds 1996, Laitinen et al. 1997, Ferrara et al. 1998, Berisha et al. 2000) as well as angiogenesis modulating factors such as angiopoietins (Ang)-1 and Ang-2 (Hazzard et al. 1999) and angiogenin (Koga et al. 2000). However, less is known about the inhibition of vessel formation, as despite the apparent production of VEGF by granulosa cells in antral follicles, angiogenesis is restricted to the theca cell layer before ovulation (Cavender \& Murdoch 1988, Gordon et al. 1995, Goede et al. 1998). Thus, the maturing follicle remains avascular before ovulation, implying that regulatory mechanisms must be present to prevent premature follicular vascularization.

The role of the avascular granuslosa layer in controlling angiogenesis in the developing follicles still appears to be controversial. Experimental evidence 
suggests that granulosa cells are also the source of angiogenesis inhibitors, such as hyaluronic acid (Tempel et al. 2000) and 2-methoxyestradiol (Shang et al. 2001). However, detailed studies investigating the cascade of events controlling angiogenesis during folliculogenesis and corpus luteum formation in the human have not been reported. This is of special interest as defects in ovarian angiogenesis contribute to a variety of disorders including anovulation and infertility, pregnancy loss, ovarian hyperstimulation syndrome, and ovarian neoplasms (Neulen et al. 1995, Abulafia \& Sherer 2000, Geva \& Jaffe 2000a).

In order to investigate the role of follicular fluid constituents and of granulosa cells in the expression of angiogenesis-related endothelial genes, human endothelial cells were incubated in vitro with human follicular fluid or culture medium conditioned by human granulosa cells. Gene expression was evaluated by microarray technology, and transcriptomes of the differently treated endothelial cells were compared with regard to the regulation of angiogenic and antiangiogenic genes.

\section{Materials and methods}

\section{Follicular fluid}

Follicular fluid was obtained by follicular aspiration from 12 follicle-stimulating hormone (FSH)-treated women (mean age 34.5 years) undergoing oocyte retrieval for in vitro fertilization (IVF/ICSI) at the Department of Gynecological Endocrinology at the University Hospital, Aachen, Germany. IVF/ICSI was performed due to andrological reasons (5), tubal occlusion (4), endometriosis (1) or idiopathic reasons (2). Ovarian stimulation was induced with recombinant human FSH (Gonal F, Serono, Unterschleissheim, Germany; mean dosage per cycle: 2300 U) after pituitary desensitization with Nafarelin (Pharmacia, Freiburg, Germany; $400 \mu \mathrm{g}$ daily intranasally). Oocyte retrieval was carried out 36-37 h after human chorionic gonadotropin (hCG) (Pregnesin, Serono) administration at a total dose of 5000 IU. After removal of oocytes, follicular fluid from each single patient was pooled (3 to 30 follicles/patient), centrifuged at $800 \boldsymbol{g}$ for $5 \mathrm{~min}$ and the supernatant was frozen at $-20{ }^{\circ} \mathrm{C}$ until use.

The experimental design was approved by the local ethical committee of the University Clinic Aachen (\# EK 2008). Written informed consent was obtained from patients individually.

\section{Granulosa cell culture}

Human granulosa cells were obtained by follicular aspiration from FSH-treated women undergoing oocyte retrieval for IVF/ICSI as described above. After centrifugation and removal of follicular fluid, the cell pellet was dissolved in $1 \mathrm{ml}$ PBS solution containing $20 \mathrm{IU}$ hyaluronidase and incubated for $12 \mathrm{~min}$ at $37^{\circ} \mathrm{C}$. Cells were washed with PBS, centrifuged, suspended in $1 \mathrm{ml}$ PBS and separated from red blood cells by centrifuging through a Percoll gradient (50\%; Biochrom, Berlin, Germany) at $2000 \boldsymbol{g}$ for $10 \mathrm{~min}$. Granulosa cells were carefully removed, suspended in $1 \mathrm{ml}$ culture medium, centrifuged at $500 \boldsymbol{g}$ for $5 \mathrm{~min}$, resuspended in $1 \mathrm{ml}$ culture medium and the cell number was evaluated. Cells were plated at a density of $5 \times 10^{5}$ cells/well in 6-well dishes (Costar, Bodenheim, Germany) and cultured in M199 Earle's Medium (Biochrom) supplemented with $10 \%$ FCS, $2 \mathrm{mM}$ L-glutamine, and $1 \%$ penicillin/ strepomycin at $37^{\circ} \mathrm{C}$ in $95 \%$ air-5\% $\mathrm{CO}_{2}$ humidified environment. Cell culture medium was changed after $24 \mathrm{~h}$ and was then harvested after 4 days of culturing and stored at $-20{ }^{\circ} \mathrm{C}$ until use in further experiments.

\section{Endothelial cell culture}

For isolation of human umbilical vein endothelial cells (HUVECs), umbilical cords were obtained immediately after term deliveries and umbilical veins were flushed with PBS, filled with $10 \mathrm{ml}$ phosphate buffered salt solution (PBS) containing $0 \cdot 1 \%$ collagenase/dispase, and incubated for $30 \mathrm{~min}$ at $37^{\circ} \mathrm{C}$. Veins were then flushed with $40 \mathrm{ml}$ culture medium which was collected in a $50-\mathrm{ml}$ tube, the cell-containing medium was centrifuged at 1200 r.p.m. for $8 \mathrm{~min}$, the pellet was resuspended in culture medium (Endothelial Cell Growth Medium-2; Clonetics, Cambrex, Vervier, Belgium) and the cells were routinely cultured as monolayers through serial passaging in $25-\mathrm{cm}^{2}$ plastic cell culture flasks (Falcon, Heidelberg, Germany). Culture medium was changed at two-day intervals. When the cultures became confluent they were passaged by exposure to $0 \cdot 05 \%$ trypsin/ 0.02\% EDTA (Gibco BRL, Germany).

For each experiment, HUVEGs of 3-5 umbilical veins were pooled and cells were seeded at a density of $0 \cdot 5 \times 10^{6}$ cells/well in 6 -well plates. After two days of culturing, cells were confluent and were incubated with 6 -ml culture medium or with $4 \cdot 5$-ml culture medium supplemented with $1.5 \mathrm{ml}$ follicular fluid or $1.5 \mathrm{ml}$ granulosa cell conditioned medium respectively. After 4 days of incubation at $37^{\circ} \mathrm{C}$ endothelial cells were harvested and frozen at $-20{ }^{\circ} \mathrm{C}$ until RNA preparation.

For single comparisons of HUVECs treated with follicular fluid, endothelial cells were separately incubated with the follicular fluid of 9 different patients and compared with 2 different controls. For array analysis of HUVECs treated with granulosa cell conditioned medium, RNA of HUVECs treated separately with the granulosa cell conditioned medium of 3 different patients was pooled and compared with pooled RNA of 3 different controls. 
Table 1 Oligonucleotide primers used for semiquantitative RT-PCR

\begin{tabular}{|c|c|c|c|c|}
\hline & Accession no. & Oligonucleotide & Sequence $\left(5^{\prime} \rightarrow 3^{\prime}\right)$ & PCR product size (bp) \\
\hline \multicolumn{5}{|l|}{ Gene } \\
\hline \multirow[t]{2}{*}{ Elastin } & NM_00501 & 5'-primer & AAAGCAGCAGCAAAGTTCGG & 288 \\
\hline & & 3'-primer & ACCTGGGACAACTGGAATCC & \\
\hline \multirow[t]{2}{*}{ Angiopoietin } & NM_001147.1 & 5'-primer & AGCTGTGATCTTGTCTTGGC & 445 \\
\hline & & 3'-primer & GTTCAAGTCTCGTGGTCTGA & \\
\hline \multirow[t]{2}{*}{ Fibulin-5 } & NM_006329.1 & 5'-primer & GCATCAATACTGAAGGCGGG & 260 \\
\hline & & 3'-primer & GCAGATGAAAGAGCCGTAGG & \\
\hline \multirow[t]{2}{*}{ Gro-beta } & M36820 & $5^{\prime}$-primer & CCGAAGTCATAGCCACACTC & 527 \\
\hline & & 3'-primer & GGCCATTTTCTTGGATTCCT & \\
\hline \multirow[t]{2}{*}{ E-selectin } & NM_000450 & $5^{\prime}$-primer & AGCCCAGAGCCTTCAGTGTA & 244 \\
\hline & & 3'-primer & AACTGGGATTTGCTGTGTCC & \\
\hline \multirow[t]{2}{*}{ VCAM-1 } & NM_001078.1 & $5^{\prime}$-primer & TAAAATGCCTGGGAAGATGG & 151 \\
\hline & & 3'-primer & GGTGCTGCAAGTCAATGAGA & \\
\hline \multirow[t]{2}{*}{$\beta$-actin } & NM_001101 & $5^{\prime}$-primer & ACCAACTGGGACGACATGGAGAAAA & 214 \\
\hline & & 3'-primer & TACGGCCAGAGGCGTACAGGGATAG & \\
\hline \multirow[t]{2}{*}{$\beta$-actin } & NM_001101 & $5^{\prime}$-primer & ACCTTCAACACCCCAGCCATGTACG & 698 \\
\hline & & 3'-primer & CTGATCCACATCTGCTGGAAGGTGG & \\
\hline
\end{tabular}

\section{Microarray analysis}

Microarray analysis was performed for each of the 9 HUVECs probes incubated with follicular fluid from different patients and for the two controls. To evaluate the effect of granulosa cell conditioned medium, one array was carried out of the pooled RNA of 3 treated HUVECs probes and one array of the pooled RNA of 3 controls.

Total RNA was isolated from HUVEGs using a Qiagen RNeasy kit (Qiagen, Hilden, Germany) according to the manufacturer's protocol. Total RNA $(8-10 \mu \mathrm{g})$ was converted into double-stranded cDNA using a modified oligo-dT primer including a $5^{\prime}$ T7 RNA polymerase promoter sequence (Dürig et al. 2003). The resulting cDNA was transcribed in vitro with T7 RNA polymerase in the presence of a mixture of ATP, CTP, UTP, GTP, biotin-11-CTP, and biotin-16-UTP as described previously (Dürig et al. 2003). Purified cRNAs were heat-fragmented in $40 \mathrm{mM}$ Tris-acetate $\mathrm{pH} 8 \cdot 1$, $100 \mathrm{mM} \mathrm{K}^{+}$acetate, and $30 \mathrm{mM} \mathrm{Mg}^{2+}$ acetate at $94{ }^{\circ} \mathrm{C}$ for 30 min. Human Genome HG-U133A microarrays (Affymetrix, High Wycombe, Herts, UK) with more than 22000 probe sets were hybridized, washed, and stained according to the manufacturer's recommendations, involving a three-step staining and amplification procedure with streptavidin-phycoerythrin (SAPE), a biotinylated anti-streptavidin antibody, and a final SAPE step. The fluorescence intensities for the individual oligonucleotide probes on the arrays were determined with a confocal scanner from Affymetrix.

Affymetrix Microarray Suite 5.0 (MAS 5.0) software was used to determine the signals and detection calls of the individual probe sets. Scaling across all probe sets (global scaling) of a given array to a target intensity of 1000 was included to compensate for variations in the amount and quality of the cRNA samples and other experimental variables. In a next step, pair wise comparison analyses of experimental and baseline arrays were performed by MAS $5 \cdot 0$ comparison analysis to determine expression changes as well as significance of change and number of comparisons which show a change, which are based on a statistical evaluation of the signals at the individual probe pair level. Filtering of the comparison results was performed using the Affymetrix Data Mining Tool 3.0. Individual cut-offs applied to the data sets are given in the legend to Table 2.

\section{RT-PCR}

RT-PGR was carried out with RNA of HUVECs treated with the follicular fluid of 10 different patients which had not been included in the microarray studies, and of 5 controls.

Total RNA $(2 \mu \mathrm{g})$ of HUVEGs was digested with DNase I (Invitrogen, Karlsruhe, Germany) for 15 min at room temperature and processed to cDNA by reverse transcription (RT) with M-MLV reverse transcriptase (Invitrogen, Karlsruhe, Germany) in a total volume of $50 \mu \mathrm{l}$. RT was performed at $37^{\circ} \mathrm{C}$ for $60 \mathrm{~min}$ in a thermocycler (Biometra, Goettingen, Germany). Four microliters of the RT-reaction were used for PGR experiments. The target and the endogenous control $(\beta$-actin) amplifications were run in one tube (for primers see Table 1). PCR reaction was performed in a $50 \mu \mathrm{l}$ volume using BioTherm Taq polymerase (Genecraft, Muenster, Germany) for 36 amplification cycles of 1 min denaturation at $94^{\circ} \mathrm{C}, 1$ min annealing at $59{ }^{\circ} \mathrm{C}$ and 1.5 min elongation at $72{ }^{\circ} \mathrm{C}$. The PCR amplification was followed by a $10-\mathrm{min}$ final extension at $72{ }^{\circ} \mathrm{C}$. The generated PCR amplification products were 
Table 2 Up- and down-regulated genes in HUVECs incubated with follicular fluid compared with controls incubated with medium only. Gene array data of 18 cross pair-wise comparisons of HUVECs treated with the follicular fluid of 9 different patients with 2 different controls. Genes were scored as differentially regulated when the following criteria were fulfilled: fold change $>2.5$ and change $P$-value $<0.001$ or fold change $<-2.5$ and change $>0.999$. Only those probe sets that fulfilled these criteria in more than $70 \%$ of the comparisons were selected for presentation. Change in gene expression is represented as mean fold change \pm standard deviation (s)

\section{Gene description}

Accession no.
Up-regulated genes
NM_020379.1
W46388
M36820
NM_001147.1
M81104.1
NM_000201.1
NM_001078.1
NM_000014.3
AF030514.1
NM_003524.1
U40053
Al817041
N95226
NM_000313.1
NM_000450.1
Down-regulated genes
AF056085.1
NM_012252.1
NM_001394.2
NM_006329.1
NM_000501
BC002700.1
NM_000903.1
NM_014331.1
NM_004915.2
NM_007361.1
NM_005010.1
gro-beta

CD34

fibulin 5 (FBLN5)

elastin

keratin 7 nidogen 2 (NID2) 1,2-alpha-mannosidase IC (HMC) superoxide dismutase 2 , mitochondrial ${ }^{*}$

angiopoietin 2 (ANGPT2)*

ICAM1, CD54*

vascular cell adhesion molecule 1 (VCAM1)

alpha-2-macroglobulin (A2M)

small inducible cytokine subfamily B (Cys-X-Cys), member $11^{\text {* }}$

H2B histone family member J (H2BFJ)

lanosterol 14-alpha-demethylase

G protein-coupled receptor

$\mathrm{G}$ protein-coupled receptor 116

protein S (alpha) (PROS1)

selectin E (endothelial adhesion molecule 1) (SELE)

GABA-B receptor, G protein-coupled receptor 51

transcription factor EC (TFEC)

dual specificity phosphatase 4 (DUSP4)*

diaphorase (NADHNADPH) (cytochrome b-5 reductase) (DIA4)*

solute carrier family 7 , member 11 (SLC7A11)*

ATP-binding cassette, sub-family $\mathrm{G}$, member 1 (ABCG1)

neuronal cell adhesion molecule (NRCAM)
18 comparisons

\begin{tabular}{|c|c|c|c|}
\hline$\times / 18$ & $\%$ & Mean & $s$ \\
\hline $18 / 18$ & 100 & $5 \cdot 3$ & 1.35 \\
\hline $18 / 18$ & 100 & $4 \cdot 6$ & 1.60 \\
\hline $18 / 18$ & 100 & $16 \cdot 5$ & 1.60 \\
\hline $17 / 18$ & 94 & 3.9 & 1.38 \\
\hline $16 / 18$ & 88 & $4 \cdot 2$ & 1.26 \\
\hline $16 / 18$ & 88 & 3.6 & $1 \cdot 21$ \\
\hline $15 / 18$ & 83 & 4.4 & 1.33 \\
\hline $14 / 18$ & 77 & $24 \cdot 3$ & 3.33 \\
\hline $14 / 18$ & 77 & $4 \cdot 2$ & 1.31 \\
\hline $14 / 18$ & 77 & 13.4 & 1.23 \\
\hline $13 / 18$ & 72 & $3 \cdot 2$ & 1.17 \\
\hline $13 / 18$ & 72 & $3 \cdot 3$ & $1 \cdot 18$ \\
\hline $13 / 18$ & 72 & 4.0 & 1.62 \\
\hline $13 / 18$ & 72 & $3 \cdot 2$ & 1.15 \\
\hline $13 / 18$ & 72 & $5 \cdot 3$ & 2.67 \\
\hline $18 / 18$ & 100 & 4.8 & 1.41 \\
\hline $17 / 18$ & 94 & $4 \cdot 7$ & 1.34 \\
\hline 17/18 & 94 & $4 \cdot 7$ & 1.35 \\
\hline $17 / 18$ & 94 & 3.5 & 1.38 \\
\hline $16 / 18$ & 88 & 14.9 & 1.93 \\
\hline $16 / 18$ & 88 & $4 \cdot 0$ & 1.28 \\
\hline $16 / 18$ & 88 & $4 \cdot 1$ & 1.38 \\
\hline $15 / 18$ & 83 & $3 \cdot 3$ & 1.19 \\
\hline $15 / 18$ & 83 & 4.7 & 1.25 \\
\hline $14 / 18$ & 77 & 3.9 & 1.31 \\
\hline $13 / 18$ & 72 & $2 \cdot 8$ & 1.05 \\
\hline
\end{tabular}

*, Results for this gene could be confirmed by two different probe sets on the array.

electrophoresed on a 2\% agarose gel and detected by ethidium bromide staining. With densitometric analysis using Gel imager (Intas, Goettingen, Germany) PCR products were normalized to $\beta$-actin and relatively quantified (Gelscan Professional V4·0, BioSciTec, Frankfurt, Germany).

The gene expression data were analyzed for statistical significance by Student's $t$-test. A $P$ value less than $0 \cdot 05$ was considered to be significant.

\section{Results}

\section{Up- and down-regulated genes in HUVECs treated with follicular fluid}

Using gene-chip expression arrays we have analyzed more than 22000 probe sets in untreated monolayers of HUVECs $(n=2)$ and compared them with the gene expression in HUVEGs treated with follicular fluid $(n=9)$, resulting in 18 comparisons. Those genes were evaluated which were significantly up- or downregulated at least $2 \cdot 5$-fold and which were regulated in more than $70 \%$ of comparisons. Using these stringent selection criteria, we identified a total of 15 genes that were up-regulated $(3 \cdot 2$ - to $24 \cdot 3$-fold) and 11 genes that were down-regulated $(3 \cdot 3-$ to $14 \cdot 9$-fold) in HUVECs treated with follicular fluid (Table 2). The regulated genes include many genes involved in angiogenesis. Up-regulated genes known to be involved in angiogenesis were gro-beta (16.5-fold increase on average), Ang-2 (3·9-fold increase), E-selectin (5·3-fold increase), alpha-2-macroglobulin (24.3-fold increase), and vascular cell adhesion molecule-1 (VCAM-1) (4-4-fold increase), whereas a significant down-regulation of fibulin-5 (3.5-fold decrease) and elastin (14.9-fold decrease) could be observed. 


\section{Up- and down-regulated genes in HUVECs treated with granulosa cell conditioned medium}

To analyze if the observed gene regulation induced by follicular fluid is mediated by factors produced by granulosa cells, HUVECs were treated with granulosa cell conditioned medium or with the corresponding follicular fluid of the same patients. Gene expression of those treated endothelial cells was compared with untreated controls by gene array analysis as described. In this experimental approach, HUVECs treated with granulosa cell conditioned medium $(n=4)$ or with follicular fluid $(n=4)$ as well as untreated controls $(n=4)$ were pooled and for each experimental approach one array was performed. Genes which showed a significant up- or down-regulation are shown in Table 3. Most of the genes found to be regulated by follicular fluid were similarly regulated by incubation with medium supernatant of granulosa cells including up-regulation of gro-beta, E-selectin and down-regulation of fibulin-5 and elastin. VCAM-1, however, which was up-regulated in endothelial cells by incubation with follicular fluid in 15 out of 18 comparisons (see Table 2), was downregulated by incubation with granulosa cell conditioned medium (Table 3). Also in this experiment, Ang-2 was up-regulated in endothelial cells by incubation with follicular fluid, but no regulation was observed after treatment with granulosa cell conditioned medium.

\section{Analysis of expression of angiogenesis-related genes by RT-PCR}

To confirm the finding of the array analysis, RT-PGR was performed in HUVECs treated with follicular fluid for those genes possibly involved in angiogenesis. A significant increase of gene expression was observed for gro-beta (43-fold), Ang-2 (1·43-fold), and E-selectin $(2 \cdot 15$-fold) compared with untreated controls (Fig. 1). The increase in VCAM-1 expression which had been observed in microarray analysis (Table 1) could be confirmed by RT-PCR (1.23-fold increase), but was not significant here. Elastin gene expression as well as mRNA expression of fibulin-5 were significantly decreased (6.8-fold and 1.48-fold respectively) in HUVEGs incubated with follicular fluid compared with untreated controls (Fig. 1).

\section{Discussion}

Our results indicate that human follicular fluid regulates the transcription of angiogenesis-related genes in endothelial cells. HUVECs incubated with medium conditioned with follicular fluid revealed a significant up-regulation of transcripts of the anti-angiogenic genes, gro-beta and Ang-2, and a significant down-regulation of the pro-angiogenic genes, fibulin-5 and elastin, whereas E-selectin was up-regulated. Similar effects were achieved for fibulin-5, elastin, gro-beta, and E-selectin by culturing HUVECs with conditioned medium from cultured human luteinized granulosa cells. Thus, in endothelial cells exposed to follicular fluid from mature follicles or to granulosa cell conditioned medium anti-angiogenic effects prevailed on the transcript level.

The most prominent up-regulated anti-angiogenic gene detected was the chemokine gro-beta (MIP-2a). Gro-beta enhances monocyte adhesion to endothelial cells (Hagiwara et al. 1998), inhibits growth factorstimulated proliferation of capillary endothelial cells, and the growth of Lewis lung tumors was curtailed by suppression of tumor-induced neovascularization (Cao et al. 1995).

A significant up-regulation could also be demonstrated for Ang-2 and for alpha-2-macroglobulin in HUVECs treated with follicular fluid; however, no significant regulation after treatment with granulosa cell conditioned medium could be observed. This could be due to too low a concentration of regulating factors secreted by granulosa cells into the culture medium. Moreover, factors contained in follicular fluid regulating these genes might originate from blood serum rather than from granulosa cells.

Ang-1 and Ang-2 are vascular endothelial cell-specific growth factors that play important roles during angiogenesis by binding to their tyrosine kinase receptor, Tie2 (Davis et al. 1996, Maisonpierre et al. 1997, Geva \& Jaffe 2000b). Ang-2 was found to disrupt blood vessel formation by antagonizing the effect of Ang-1 and Tie2, and was thus considered to represent a natural Ang-1/Tie2 inhibitor (Maisonpierre et al. 1997, Asahara et al. 1998). The balance between the Ang-2:Ang-1 ratio and VEGF expression is important for the regulation of angiogenesis (Goede et al. 1998, Wulff et al. 2000) and the Ang/Tie system is supposed to be involved in the angiogenetic changes that occur during follicular development (Maisonpierre et al. 1997, Goede et al. 1998, Hazzard et al. 1999, Wulff et al. 2000, Hayashi et al. 2003) as well as in pathological angiogenesis in the ovary (Hata et al. 2002). The proteinase inhibitor alpha-2-macroglobulin has been shown to bind to VEGF (Bhattacharjee et al. 2000) and thus may have an influence on VEGF action. The up-regulation of alpha-2 macroglobulin gene expression also supports antiangiogenic properties of follicular fluid.

In contrast to these results, transcription of the pro-angiogenic factors elastin and fibulin-5 was significantly down-regulated in endothelial cells treated with follicular fluid or granulosa cell conditioned medium. Fibulin-5 (also known as EVEC/DANCE) is an integrin-binding extracellular matrix protein abundantly expressed in vascular endothelial cells of vessels which contain elastic fibers and in developing arteries 


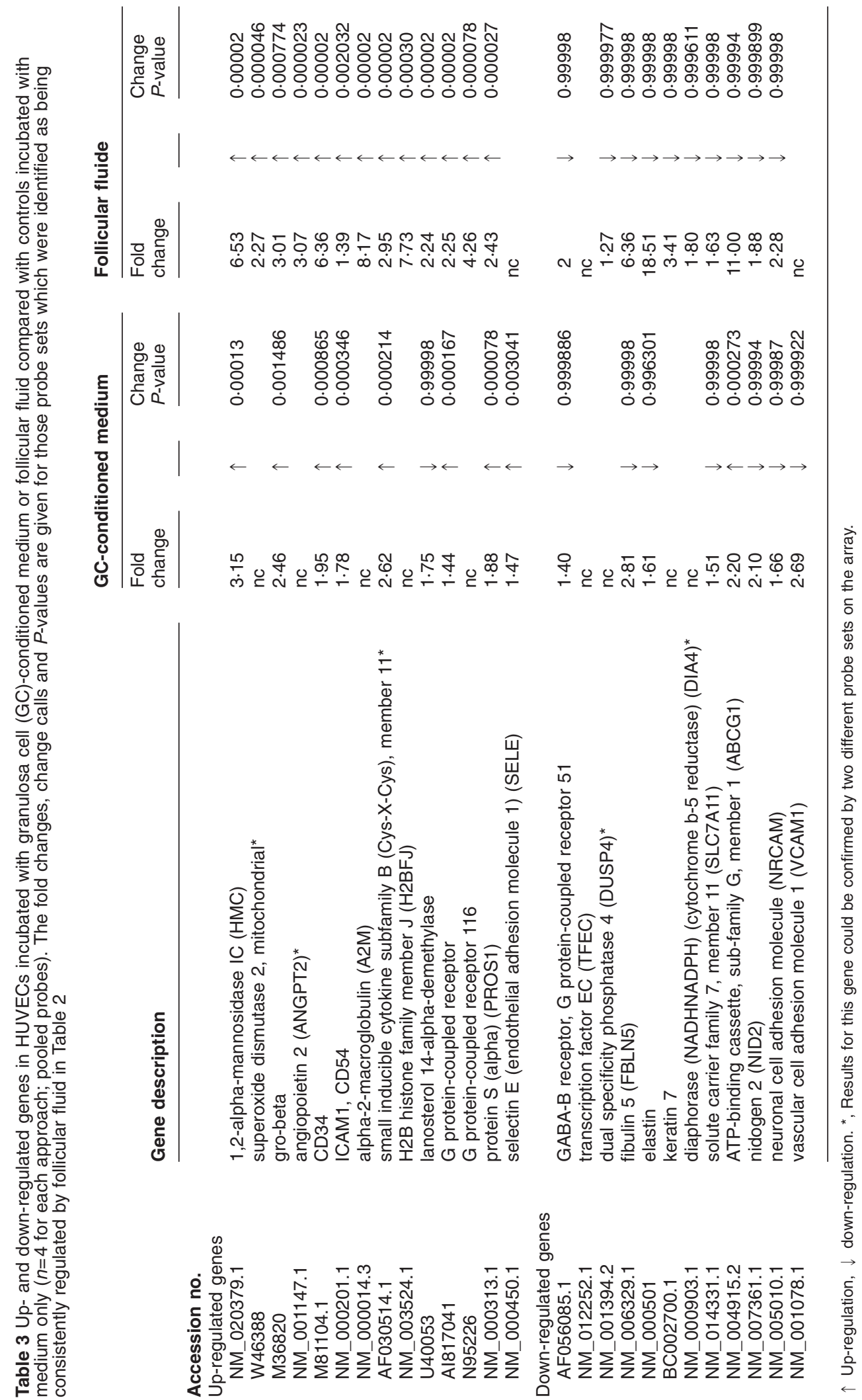




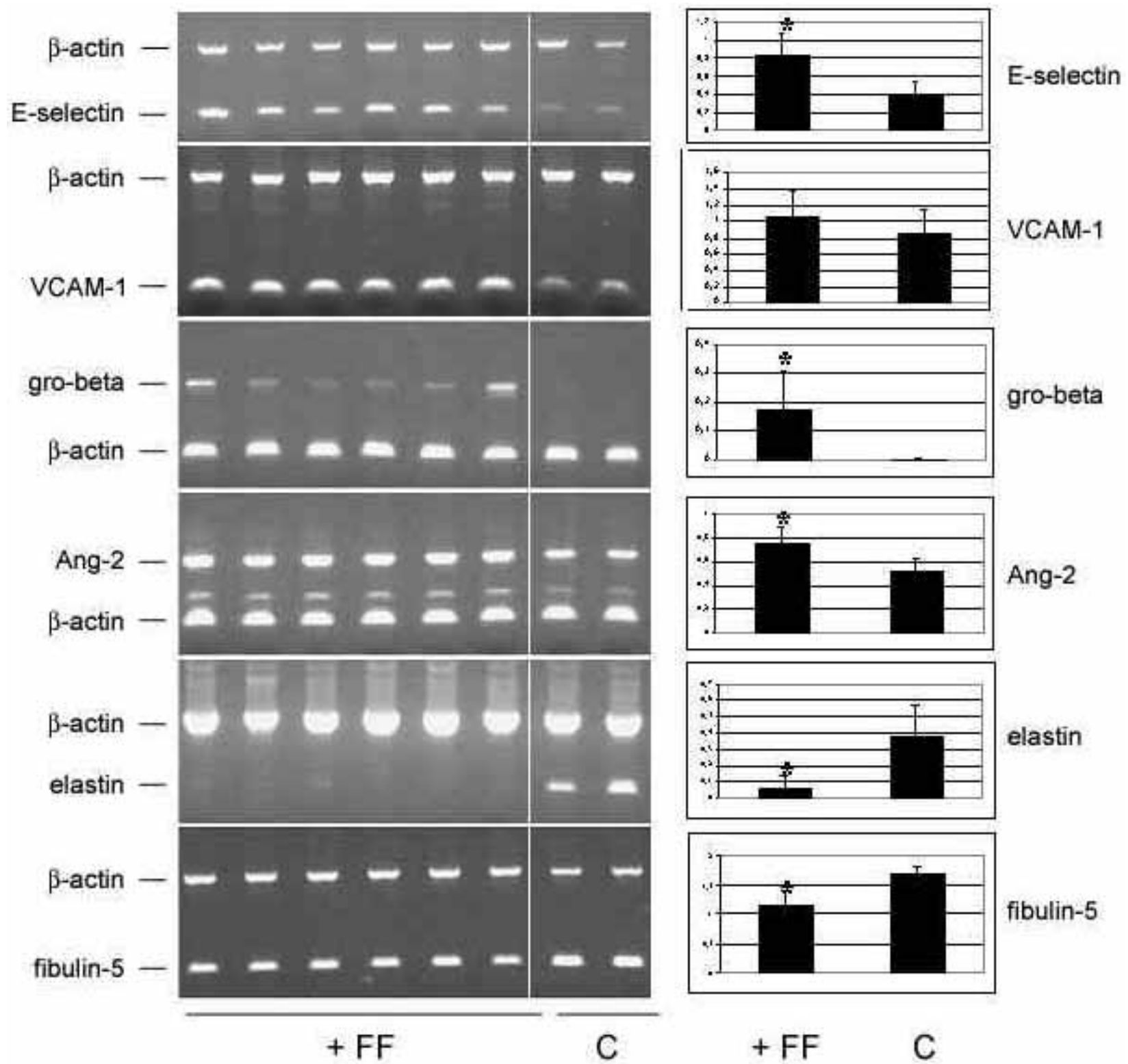

Figure 1 RT-PCR (one representative gel for each experimental design) and densitometric analysis of expression of E-selectin, VCAM-1, gro-beta, angiopoietin-2 (Ang-2), elastin, and fibulin-5 in HUVECs incubated with medium containing follicular fluid $(F F, n=10)$ or with culture medium only $(C, n=5)$ for 4 days. While expression of E-selectin, gro-beta and angiopoietin-2 were significantly enhanced in endothelial cells treated with follicular fluid, expression of elastin and fibulin-5 were significantly suppressed compared with controls. Bars represent mean values+standard deviation. ${ }^{*}=P<0.05$. $\beta$-Actin was used as a standard for densitometric evaluation.

(Kowal et al. 1999, Nakamura et al. 1999). In addition, it provides anchorage of elastic fibers to cells by binding to elastin, thereby stabilizing and organizing elastic fibers in the vasculature (Midwood \& Schwarzbauer 2002, Nakamura et al. 2002, Yanagisawa et al. 2002, Kuang et al. 2003).

The expression of fibulin-5 is up-regulated during vascular growth and maturation in lesions of injured vessels (Kowal et al. 1999). It could be shown that the absence of fibulin-5 did not alter the proliferative effect of elastin, but rather perturbed elastic fiber architecture (Nakamura et al. 2002). In addition to its structural function, elastin provides an anti-proliferative effect on vascular smooth muscle cells, and elastin null mice died perinatally due to vascular occlusion $(\mathrm{Li}$ et al. 1998). 
E-selectin is a calcium-dependent lectin that mediates adhesive interactions of circulating leucocytes with the vascular endothelium. It is synthesized and expressed on activated endothelial cells and can be induced by inflammatory cytokines (Bevilacqua et al. 1987, Carlos \& Harlan 1994). Elevated levels of soluble E-selectin have been found in patients with vasculoproliferative disorders such as rheumatoid arthritis (Koch et al. 1993) and tumor growth (Benekli et al. 1998, Hebbar \& Peyrat 2000). E-selectin is a potent angiogenic mediator as it could be shown to induce an increase in HUVEC tube formation in the Matrigel in vitro assay (Kumar et al. 2003). VCAM-1 has been correlated to angiogenesis and could be detected in human follicular fluid (Benifla et al. 2001). In the microarray analysis, the expression of VCAM-1 was enhanced in HUVECs incubated with follicular fluid; however, this regulation was not confirmed as significant using RT-PGR.

Recently, experimental evidence suggested that granulosa cells produce and follicular fluid contains pro-angiogenic cytokines such as VEGF (Ravindranath et al. 1992, Yan et al. 1993, Kamat et al. 1995, Neulen et al. 1995, 1998, Doldi et al. 1997, Laitinen et al. 1997, Otani et al. 1999, Berisha et al. 2000). In addition to pro-angiogenic molecules, negative regulators of angiogenesis were observed (Tempel et al. 2000, Shang et al. 2001, Grasselli et al. 2003). The present work demonstrates that factors contained in follicular fluid regulate the transcription of angiogenesis-modulating genes in endothelial cells and thus could help to explain the temporal and spatial discrepancy between the high expression of VEGF and the restricted angiogenesis in the preovulatory follicle. Follicular fluid may provide a molecular shield that prevents premature vascularization of the preovulatory follicle. The balance of these regulatory factors is presumed to change according to the stage of follicular development. Though follicular fluid and granulosa cells were isolated from IVF patients and thus had been exposed to hCG, they were still pre-ovulatory and can be helpful to evaluate molecular mechanisms involved in the regulation of ovarian angiogenesis.

HUVECs exposed to follicular fluid or luteinized human granulosa cell conditioned media exhibit both the expression of pro- and anti-angiogenic genes. Angiogenesis is strictly controlled by a balance of proand anti-angiogenic regulators (Hanahan \& Folkman 1996) resulting in temporal and spatial tightly regulated angiogenesis and vessel function. Our data suggest the production of angiogenesis-modulating factors by granulosa cells of peri-ovulatory follicles in humans with regard to gene transcription. However, the regulation of protein level as well as the impact on the biological function of endothelial cells still has to be evaluated. Understanding the molecular mechanisms which regulate the complex process of angiogenesis is a major challenge, with implications for the understanding of angiogenesis in reproductive biology as well as in pathological conditions.

\section{Acknowledgements}

This work was supported by the Deutsche Forschungsgemeinschaft GR 1138/8 to R G and J N.

\section{References}

Abulafia O \& Sherer DM 2000 Angiogenesis of the ovary. American Journal of Obstetrics and Gynecology 182 240-246.

Asahara T, Chen D, Takahashi T, Fujikawa K, Kearney M, Magner M, Yancopoulos GD \& Isner JM 1998 Tie2 receptor ligands, angiopoietin-1 and angiopoietin-2, modulate VEGF-induced postnatal neovascularization. Circulation Research 83 233-240.

Augustin HG 2000 Vascular morphogenesis in the ovary. Baillieres Best Practical Research of Clinical Obstetrics and Gynaecology 14 867-882.

Benekli M, Gullu IH, Tekuzman G, Savas MC, Hayran M, Hascelik G \& Firat D 1998 Circulating intercellular adhesion molecule-1 and E-selectin levels in gastric cancer. British Fournal of Cancer $\mathbf{7 8}$ 267-271.

Benifla JL, Bringuier AF, Sifer C, Porcher R, Madelenat P \& Feldmann G 2001 Vascular endothelial growth factor, platelet endothelial cell adhesion molecule-1 and vascular cell adhesion molecule-1 in the follicular fluid of patients undergoing IVF. Human Reproduction 16 1376-1381.

Berisha B, Schams D, Kosmann M, Amselgruber W \& Einspanier R 2000 Expression and localisation of vascular endothelial growth factor and basic fibroblast growth factor during the final growth of bovine ovarian follicles. Fournal of Endocrinology 167 371-382.

Bevilacqua MP, Pober JS, Mendrick DL, Cotran RS \& Gimbrone MA 1987 Identification of an inducible endothelial-leukocyte adhesion molecule. PNAS 84 9238-9242.

Bhattacharjee G, Asplin IR, Wu SM, Gawdi G \& Pizzo SV 2000 The conformation-dependent interaction of alpha 2-macroglobulin with vascular endothelial growth factor. A novel mechanism of alpha 2-macroglobulin/growth factor binding. Fournal of Biological Chemistry 275 26806-26811.

Cao Y, Chen C, Weatherbee JA, Tsang M \& Folkman J 1995 Gro-beta, a - C-X-C-chemokine, is an angiogenesis inhibitor that suppresses the growth of Lewis lung carcinoma in mice. Fournal of Experimental Medicine 182 2096-2077.

Carlos TM \& Harlan JM 1994 Leukocyte-endothelial adhesion molecules. Blood 84 2068-2101.

Cavender JL \& Murdoch WJ 1988 Morphological studies of the microcirculatory system of periovulatory ovine follicles. Biology of Reproduction 39 989-997.

Davis S, Aldrich TH, Jones PF, Acheson A, Compton DL, Jain V, Ryan TE, Bruno J, Radziejewski C, Maisonpierre PC \& Yancopoulos GD 1996 Isolation of angiopoietin-1, a ligand for the TIE2 receptor, by secretion-trap expression cloning. Cell $\mathbf{8 7}$ $1161-1169$.

Doldi N, Bassan M, Messa A \& Ferrari A 1997 Expression of vascular endothelial growth factor in human luteinizing granulosa cells and its correlation with the response to controlled ovarian hyperstimulation. Gynecological Endocrinology 11 263-267.

Dürig J, Nuckel H, Huttmann A, Kruse E, Holter T, Halfmeyer K, Fuhrer A, Rudolph R, Kalhori N, Nusch A, Deaglio S, Malavasi F, Möröy T, Klein-Hitpass L \& Duhrsen U 2003 Expression of ribosomal and translation-associated genes is correlated with a favorable clinical course in chronic lymphocytic leukemia. Blood $1012748-2755$. 
Ferrara N, Chen H, Davis-Smyth T, Gerber HP, Nguyen TN, Peers D, Chisholm V, Hillan KJ \& Schwall RH 1998 Vascular endothelial growth factor is essential for corpus luteum angiogenesis. Nature Medicine 4 336-340.

Findlay JK 1986 Angiogenesis in reproductive tissues. Fournal of Endocrinology $111357-366$.

Fraser HM \& Wulff C 2001 Angiogenesis in the primate ovary. Reproduction, Fertility and Development 13 557-566.

Geva E \& Jaffe RB 2000a Role of vascular endothelial growth factor in ovarian physiology and pathology. Fertility and Sterility $\mathbf{7 4}$ 429-438.

Geva E \& Jaffe RB $2000 b$ Role of angiopoietins in reproductive tract angiogenesis. Obstetrical and Gynecological Survey 55 511-519.

Goede V, Schmidt T, Kimmina S, Kozian D \& Augustin HG 1998 Analysis of blood vessel maturation processes during cyclic ovarian angiogenesis. Laboratory Investigation 78 1385-1394.

Gordon JD, Shifren JL, Foulk RA, Taylor RN \& Jaffe RB 1995 Angiogenesis in the human female reproductive tract. Obstetrical and Gynecological Survey 50 688-697.

Grasselli F, Basini G, Tirelli M, Cavalli V, Bussolati S \& Tamanini C 2003 Angiogenic activity of porcine granulosa cells co-cultured with endothelial cells in a microcarrier-based three-dimensional fibrin gel. Fournal of Physiology and Pharmacology 54 361-370.

Hagiwara H, Mitsumata M, Yamane T, Jin X \& Yoshida Y 1998 Laminar shear stress-induced gro mRNA and protein expression in endothelial cells. Circulation 98 2584-2590.

Hanahan D \& Folkman J 1996 Patterns and emerging mechanisms of the angiogenic switch during tumorigenesis. Cell $\mathbf{8 6}$ 353-364.

Hata K, Udagawa J, Fujiwaki R, Nakayama K, Otani H \& Miyazaki K 2002 Expression of angiopoietin-1, angiopoietin-2, and Tie2 genes in normal ovary with corpus luteum and in ovarian cancer. Oncology 62 340-348.

Hayashi KG, Acosta TJ, Tetsuka M, Berisha B, Matsui M, Schams D, Ohtani M \& Miyamoto A 2003 Involvement of angiopoietin-tie system in bovine follicular development and atresia: messenger RNA expression in theca interna and effect on steroid secretion. Biology of Reproduction 69 2078-2084.

Hazzard TM, Molskness TA, Chaffin CL \& Stouffer RL 1999 Vascular endothelial growth factor (VEGF) and angiopoietin regulation by gonadotrophin and steroids in macaque granulosa cells during the peri-ovulatory interval. Molecular Human Reproduction 5 1115-1121.

Hebbar M \& Peyrat JP 2000 Significance of soluble endothelial molecule E-selectin in patients with breast cancer. International Fournal of Biological Markers 15 15-21.

Kamat BR, Brown LF, Manseau EJ, Senger DR \& Dvorak HF 1995 Expression of vascular permeability factor/vascular endothelial growth factor by human granulosa and theca lutein cells. Role in corpus luteum development. American Fournal of Pathology 146 $157-165$.

Koch AE, Turkiewicz W, Harlow LA \& Pope RM 1993 Soluble E-selectin in arthritis. Clinical Immunology and Immunopathology 69 29-35.

Koga K, Osuga Y, Tsutsumi O, Momoeda M, Suenaga A, Kugu K, Fujiwara T, Takai Y, Yano T \& Taketani Y 2000 Evidence for the presence of angiogenin in human follicular fluid and the up-regulation of its production by human chorionic gonadotropin and hypoxia. Fournal of Clinical Endocrinology and Metabolism $\mathbf{8 5}$ 3352-3355.

Kowal RC, Richardson JA, Miano JM \& Olson EN 1999 EVEC, a novel epidermal growth factor-like repeat-containing protein upregulated in embryonic and diseased adult vasculature. Circulation Research 84 1166-1176.

Kuang PP, Goldstein RH, Liu Y, Rishikof DC, Jean JC \& Joyce-Brady M 2003 Coordinate expression of fibulin-5/DANCE and elastin during lung injury repair. American Fournal of Physiology: Lung Cellular and Molecular Physiology 285 1147-1152.
Kumar P, Amin MA, Harlow LA, Polverini PJ \& Koch AE 2003 Src and phosphatidylinositol 3-kinase mediate soluble E-selectin-induced angiogenesis. Blood 101 3960-3968.

Laitinen M, Ristimaki A, Honkasalo M, Narko K, Paavonen K \& Ritvos O 1997 Differential hormonal regulation of vascular endothelial growth factors VEGF, VEGF-B, and VEGF-C messenger ribonucleic acid levels in cultured human granulosa-luteal cells. Endocrinology 138 4748-4756.

Li DY, Brooke B, Davis EC, Mecham RP, Sorensen LK, Boak BB, Eichwald E \& Keating MT 1998 Elastin is an essential determinant of arterial morphogenesis. Nature 393 276-280.

Maisonpierre PC, Suri C, Jones PF, Bartunkova S, Wiegand SJ, Radziejewski C, Compton D, McClain J, Aldrich TH,

Papadopoulos N, Daly TJ, Davis S, Sato TN \& Yancopoulos GD 1997 Angiopoietin-2, a natural antagonist for Tie2 that disrupts in vivo angiogenesis. Science 277 55-60.

Midwood KS \& Schwarzbauer JE 2002 Elastic fibers: building bridges between cells and their matrix. Current Biology 12 R279-R281

Moor RM \& Seamark RF 1986 Cell signaling, permeability, and microvasculatory changes during antral follicle development in mammals. Fournal of Dairy Science 69 927-943.

Nakamura T, Ruiz-Lozano P, Lindner V, Yabe D, Taniwaki M, Furukawa Y, Kobuke K, Tashiro K, Lu Z, Andon NL, Schaub R, Matsumori A, Sasayama S, Chien KR \& Honjo T 1999 DANCE, a novel secreted RGD protein expressed in developing, atherosclerotic, and balloon-injured arteries. Fournal of Biological Chemistry $27422476-22483$.

Nakamura T, Lozano PR, Ikeda Y, Iwanaga Y, Hinek A, Minamisawa S, Cheng CF, Kobuke K, Dalton N, Takada Y, Tashiro K, Ross J, Honjo T \& Chien KR 2002 Fibulin-5/DANCE is essential for elastogenesis in vivo. Nature 415 $171-175$.

Neulen J, Yan Z, Raczek S, Weindel K, Keck C, Weich HA, Marme D \& Breckwoldt M 1995 Human chorionic gonadotropin-dependent expression of vascular endothelial growth factor/vascular permeability factor in human granulosa cells: importance in ovarian hyperstimulation syndrome. Fournal of Clinical Endocrinology and Metabolism 80 1967-1971.

Neulen J, Raczek S, Pogorzelski M, Grunwald K, Yeo TK, Dvorak HF, Weich HA \& Breckwoldt M 1998 Secretion of vascular endothelial growth factor/vascular permeability factor from human luteinized granulosa cells is human chorionic gonadotrophin dependent. Molecular Human Reproduction 4 203-206.

Otani N, Minami S, Yamoto M, Shikone T, Otani H, Nishiyama R, Otani T \& Nakano R 1999 The vascular endothelial growth factor/fms-like tyrosine kinase system in human ovary during the menstrual cycle and early pregnancy. Fournal of Clinical Endocrinology and Metabolism 84 3845-3851.

Ravindranath N, Little-Ihrig L, Phillips HS, Ferrara N \& Zeleznik AJ 1992 Vascular endothelial growth factor messenger ribonucleic acid expression in the primate ovary. Endocrinology $131254-260$.

Redmer DA \& Reynolds LP 1996 Angiogenesis in the ovary. Reviewes of Reproduction 1 182-192.

Reynolds LP, Killilea SD \& Redmer DA 1992 Angiogenesis in the female reproductive system. FASEB fournal 6 886-892.

Shang W, Konidari I \& Schomberg DW 2001 2-Methoxyestradiol, an endogenous estradiol metabolite, differentially inhibits granulosa and endothelial cell mitosis: a potential follicular anti-angiogenic regulator. Biology of Reproduction 65 622-627.

Tempel C, Gilead A \& Neeman M 2000 Hyaluronic acid as an anti-angiogenic shield in the preovulatory rat follicle. Biology of Reproduction 63 134-140.

Wulff C, Wilson H, Largue P, Duncan WC, Armstrong DG \& Fraser HM 2000 Angiogenesis in the human corpus luteum: localization and changes in angiopoietins, Tie-2, and vascular endothelial growth factor messenger ribonucleic acid. Fournal of Clinical Endocrinology and Metabolism 85 4302-4309. 
Yan Z, Weich HA, Bernart W, Breckwoldt M \& Neulen J 1993 Vascular endothelial growth factor (VEGF) messenger ribonucleic acid (mRNA) expression in luteinized human granulosa cells in vitro. Fournal of Clinical Endocrinology and Metabolism 77 1723-1725.

Yanagisawa H, Davis EC, Starcher BC, Ouchi T, Yanagisawa M, Richardson JA \& Olson EN 2002 Fibulin-5 is an elastin-binding protein essential for elastic fibre development in vivo. Nature 415 $168-171$.

Received 30 August 2004

Accepted 6 October 2004

Made available online as an Accepted Preprint 20 October 2004 